\title{
Los medios de comunicación y la transformación del hombre en la literatura distópica 1
}

The media and the transformation of man in dystopian literature

RUDINEI KOPP2

(Traducción: Alejandro Tapia3)

La primera mitad del siglo XX es el momento en el cual se hace evidente la emergencia de la literatura distópica. En textos como Nosotros, Un Mundo Feliz, 1984, La Pianola y Farenheit 451, los medios de comunicación son representados de forma crítica y tendrían la función de moldear al hombre y a la sociedad de acuerdo a propósitos totalitarios de organización social.

PALABRAS CLAVE: Literatura distópica, comunicación de masashistoria, comunicación de masas y tecnología.
The first half of the Twentieth Century was witness to the great boom of dystopian literature. In texts such as Brave New World, 1984, Piano Player and Fahrenheit 451, the mass communication media are critically shown as responsible for shaping of man as well as society in conformity with totalitarian purposes of social organization.

KEY WORDS: Dystopian literature, mass media-History, mass communication and technology.

1 Investigación Financiada por la Universidade de Santa Cruz do Sul.

2 Universidad de Santa Cruz do Sul, Brasil.

Correo electrónico: rudinei@unisc.br

Av. Independência 2293, C.P. 96815-900; Santa Cruz do Sul, Río Grande do Sul, Brasil.

3 Universidad Autónoma Metropolitana-Xochimilco, México.

Correo electrónico: hipotrelico@gmail.com

Calz. del Hueso 1100, Col. Villa Quietud, C.P. 04960; D.F., México. 
En los últimos años se ha despertado un nuevo interés por las temáticas distópicas y ello se ha revelado, especialmente, en filmes y libros dirigidos a los grandes públicos. Vemos así historias que ofrecen tramas que suceden en futuros que son imaginados como tiempos peores a los actuales, y las cuales se transforman en fenómenos de mercado.

Un ejemplo reciente y notorio de lo anterior es la serie Los Juegos del Hambre (2008), de Suzanne Collins. En este caso se trata de una saga literaria dirigida al público infantil y juvenil que tuvo un gran éxito en las ventas (y con las traducciones fuera de Estados Unidos el éxito continúa multiplicándose), mientras que la versión cinematográfica terminó alcanzando, igualmente, un gran éxito comercial. Así mismo, hay otros libros y series que han seguido esa tendencia, pero tal fenómeno no es algo realmente muy reciente.

La producción y el interés por las narrativas con formas distópicas, sin embargo, no es algo que haya nacido en los primeros años de este siglo. La literatura distópica tiene ya una buena trayectoria y es común considerar que sus obras canónicas estén identificadas con la primera mitad del siglo XX, especialmente en el periodo de entre y postguerras. Textos como Nosotros, de Eugene Zamiatin (1924; Un Mundo Feliz, de Aldous Huxley (1932); 1984, de George Orwell (1949); La Pianola, de Kurt Vonnegut Jr. (1952) y Fahrenheit 451, de Ray Bradbury (1953), formaron un conjunto fundamental para entender el surgimiento de la distopía como gran fuerza creativa y crítica en el registro y la construcción del imaginario de esa época.

\section{IMAGINACIÓN DISTÓPICA Y TECNOLOGÍA}

Para Keith Booker (1994b) un punto de partida fundamental en relación con el estudio de la ficción distópica es la noción de que ella es una defensa "más de compromiso político que de ficción en su sentido literario." El autor demuestra que "la ficción distópica funciona frecuentemente como una forma de crítica social y política que hace eco del trabajo de innumerables teóricos y críticos de la cultura moderna" (p. 174). Es sobre todo la caja de resonancia de una época. El impulso distópico sería como un "punto focal para confrontaciones polifónicas entre literatura, cultura popular y crítica social" pero ante ello: 
Nosotros, como analistas, podemos contribuir al desafío que es, fundamentalmente, algo positivo. De hecho, puede ser que las advertencias utópicas sirvan para impedir que los paralelos sean, en último análisis, necesarios para preservar alguna posibilidad de soñar con un futuro mejor (Booker, 1994b, p. 177).

Las sociedades en las cuales vivían esos escritores podían no ser un sueño sobre la Tierra, pero tales mundos no eran, por lo menos no todavía, semejantes a lo que proyectaban. En los mundos que ellos imaginaron simplemente no habían condiciones para que sus libros existieran. Sea porque estarían prohibidos, sea porque no habría más espíritu creativo para escribirlos, o porque ellos serían económicamente inviables o, más aún, porque ni siquiera habría el menor interés por los libros: no habría, en fin, lectores. Hasta dónde ese tipo de texto puede haber contribuido a que la sociedad no se encaminase completamente a lo que ahí se dibujaba es un misterio. Si llegó a existir o hay una sociedad tecnológica y totalitaria, esta se organizó de forma más sutil -y, entonces, sería hasta más tecnológicamente eficiente- que aquellas presentadas en las ficciones distópicas referidas, mientras que los medios de comunicación existentes, en términos tecnológicos, parecen hasta más fantásticos de lo que esa ficción imaginó. La alerta, sin embargo, tiene aún validez: resuena todavía en la sociedad contemporánea en la medida en que se lee a esos textos en sus pretensiones, como define Russel Jacoby (2007), más iconoclastas y menos proyectivas.

Para la crítica, a partir de ello, la cuestión no sería tanto la de considerar si esos autores son tecnofóbicos. Queda muy claro en los textos que el maquinismo que permea la vida, la organización de la sociedad y la constitución de los medios de comunicación, es siempre resultante de una intención humana, de una empresa, de un proyecto, de un plan. Raymond Williams (1992) destaca la necesidad de observar y analizar cómo los medios de comunicación plantean las cosas. Éstos tienden a aislar o polarizar las relaciones entre la "invención técnica" y la "sociedad", reduciendo las perspectivas a dos caminos: "los inventos técnicos cambian a la sociedad" o "la sociedad determina los usos de los inventos técnicos" (p. 184). Para Williams, la cuestión no puede ser resumida tan fácilmente y la visión sobre el asunto se ampliaría al: 
Ver que los inventos técnicos se dan siempre dentro de las sociedades, y que las sociedades son siempre algo más que una suma de relaciones e instituciones de las cuales los inventos técnicos hayan sido excluidos mediante una definición falsamente especializada (p. 184).

De acuerdo con el autor, ello se torna todavía más problemático en la medida en que se confunden los "inventos técnicos" con "tecnología" y ambos pasan a ser tratados como equivalentes. Para Williams, la distinción -que nunca significa una separación-debe ser clarificada:

La técnica de la escritura es una cosa, pero la tecnología de la escritura implicó no sólo el desarrollo de instrumentos y materiales para la escritura, sino también el desarrollo de un cuerpo más amplio de conocimientos y, especialmente, de la habilidad para leer que, en la práctica, era inseparable de las formas más genéricas de la organización social ... Así, la relación entre una tecnología y sus instituciones más comunes se convirtió en una base -en un principio- de diferenciaciones sociales específicas y, más tarde, inevitablemente, de conflictos sociales (pp. 190-191).

El mundo occidental, en la primera mitad del siglo XX, no presencia todavía, como en un palco, los recursos y aparatos técnicos característicos de esa época. Se encuentra marcado por la tecnología porque ese es el modo de existencia que produce y ratifica. La mirada que se lanza para el futuro, sin embargo, es de ansiedad, mientras que el conocimiento científico, la capacidad tecnológica disponible, las formas de gobierno, las opciones ideológicas y los sistemas económicos son transformados; a través de las lentes distópicas, se convierten en los motores que harían que los tiempos por vivir fueran imaginados como mundos peores, marcados por la transformación del hombre y de la sociedad en algo indeseable y, sobre todo, peor.

Kumar (1987) afirma que "después de la Primera Guerra Mundial, las utopías están en retroceso por todas partes. Los años de 1920, 1930 y 1940 fueron la era clásica de las 'utopías en negativo', de las antiutopías o distopías" (p. 224). Ellas son las décadas malditas, los años de persecuciones y desempleo en masa, de los dictadores brutales y de las guerras mundiales. Si esas son las condiciones históricas más 
evidentes y visibles, hay también un cuadro que se refiere al estado de ánimo que asolaba al pensamiento de esa época y ciertas cuestiones que eran apremiantes y definidoras de la sociedad como un todo. Un campo que se encuadra en la intersección entre ficción distópica, pensamiento, y modo de vida, es la tecnología. Ciertamente no se trata de un periodo identificado solo por los conflictos y las tragedias, sino que está lejos de ser la realización de un ideal de paz entre los hombres.

En Technology and Dystopia, ${ }^{4}$ Walter Fogg (1975), se dedica a proponer cuestiones que relacionan la forma como la tecnología ha sido representada en la ficción distópica del siglo XX. Para él, esos textos "son predominantemente extrapolaciones de aquello que los escritores sienten respecto a los efectos destructivos y deshumanizantes de la tecnología y de los cambios tecnológicos" (p. 67). A partir de ello enfatiza tres temas que considera recurrentes en la ficción distópica.

1. "La destrucción y transformación de la naturaleza" es uno de esos puntos. El autor destaca que para el desarrollo y perfeccionamiento de las formas de generación de energía, el hombre cuenta, cada vez más, con recursos poderosos que poseen, en la misma intensidad, la capacidad de mantener la vida que de destruirla. A partir de esas interferencias, la naturaleza, como un todo, sufre modificaciones que vuelven la vida del hombre algo amenazado. De acuerdo con Fogg (1975), parece haber constantemente, en esos abordajes, la idea de que "hay cosas que el hombre no debería saber" (p. 68).

2. "La sociedad manipulada" es otro ítem identificado por Fogg. Para sustentar ese grupo, el autor recuerda que buena parte de las cosas que Bacon (2006) proyectó como innovaciones imaginadas en La Nueva Atlántida pasaron a formar parte de la vida en el siglo XX. "La Casa de Salomón" estaba estrechamente ligada al poder político en Bensalem y, a partir de eso, se vuelve protagonista de tal relación. Fogg (1975) afirma que en las distopías un tema recurrente es "precisamente el

4 Artículo relativamente breve (pp. 57-73) publicado en la colección Utopia/ Dystopia?, organizada por Peyton E. Richter (Universidad de Boston), pero que ha sido una referencia recurrente y fundamental en las reflexiones sobre las relaciones entre tecnología, utopía y distopía. 
miedo de que ello fuera a suceder en la sociedad moderna y el control directo de esa sociedad del futuro acabase en las manos de una élite de científicos-técnicos que definieran las reglas a partir de sus propias normas de eficiencia y producción" (p. 69). El temor se proyecta, de acuerdo con Fogg, en las ficciones distópicas, en tecnocracias que se sobreponen a la participación democrática.

3. Otro tema es "el hombre manipulado". En este caso, las "amenazas" de la tecnología pueden manifestarse en "campos como la psicología conductual, en la biogenética, en la psicofarmacología y la neurocirugía como posibilidades de un condicionamiento completo del ser humano, retirándole así su libertad e individualidad" (Fogg, 1975, p. 68). Para ello son empleadas técnicas diversas de intervención: drogas, implantes, manipulación genética o condicionamiento psicológico. En tales condiciones, el hombre acaba perdiendo la capacidad de tener la soberanía sobre su destino. Puede volverse, como criatura manipulada, un robot humano, un autómata, un ser completamente vigilado, un alienado desconectado de la realidad, y así sucesivamente.

De forma general, Fogg (1975) considera que para esos escritores la tecnología representa la condición total de hombre occidental moderno, una visión de mundo, un conjunto de valores y un modo de pensamiento: "esos escritores sienten que la visión del mundo tecnocientífica ha corroído otros modos de pensamiento y estilos de vida, además de haber desmitificado el mundo del hombre a fin de tornarlo un ser tecnológicamente administrable" (p. 70).

Esta observación es, objetivamente, el dibujo de una sociedad tecnológica y tanto el hombre como la propia sociedad se convertirían, dentro de esas visiones, en objetos calculables y adaptables a un mundo "tecnológicamente administrable". El contexto a partir del cual emergen los textos distópicos que son mencionados aquí es de amplio desarrollo tecnológico y ello representaba una fuente de preocupación y de dudas entre los escritores y pensadores identificados con una mirada crítica sobre la sociedad. Al mismo tiempo que surgen y se desarrollan nuevas soluciones, aparatos, inventos diversos, sistemas de organización y producción e, incluso, revoluciones en diversas áreas de conocimiento atesoradas cada día por la ciencia y la tecnología, surgen también reflexiones de analistas que encaran ese periodo de forma desconfiada. 
Las sociedades proyectadas en los cinco textos analizados, a diferencia de la ficción utópica tan característica del siglo XIX, no revelan la buena voluntad del hombre. Tales sociedades son regidas por una noción de organización y esquematización que se basa en la manutención suprema de una meta, que se impone a las individualidades del hombre común, y cada aspecto de la vida es planificado. No existe más una práctica vinculada a la tradición o a un conjunto de hábitos sin propósitos utilitarios; nada más es espontáneo o el resultado de eventos exteriores al poder centralizado. Si esa condición de organización social no era todavía un retrato absoluto y completamente fiel de la sociedad industrial moderna de Europa o de Estados Unidos, sí era lo que se imaginaba como virtualmente admitido o una potencialidad que se materializaba, cada vez más, como hegemónica. Pensadores como Oswald Spengler, José Ortega y Gasset, Nicolai Berdiaeff, Lewis Mumford, Jacques Ellul o Herbert Marcuse -y la lista podría extenderse- observan que la tendencia tecnologizante de esa sociedad conduce al hombre a una vida en la cual este se transforma en un móvil incapaz de definir o de imaginar su destino autónomamente.

\section{LOS MEDIOS DE COMUNICACIÓN COMO HERRAMIENTAS DE TRANSFORMACIÓN DEL HOMBRE}

En los textos analizados hay una amplia tecnología para transformar al hombre y para mantenerlo, posteriormente, en un estado de conformidad ideal para la permanencia del poder establecido. Desde el nacimiento hay sistemas de control que son aplicados para que la educación, la relación con los grupos primarios, el trabajo, la diversión, los castigos, la enfermedad y la muerte sean administrados con el propósito de hacer del ser humano el resultado de un plan.

Conforme a Mumford (1960):

Para sobrevivir en ese mundo, 5 el hombre mismo debe adaptarse por completo a la máquina. Los tipos inadaptables, como el artista o el poeta, el santo o el campesino, serán remodelados o eliminados por la selección social.

5 El autor se refería a la primera mitad de siglo XX. 
Toda facultad creadora relacionada con la religión o con la cultura del Viejo Mundo tenderá a desaparecer. Hacerse más humano, profundizar más en la naturaleza del hombre, perseguir lo divino, ya no son más objetivos adecuados para el hombre mecánico (p. 182).

Ese "hombre mecánico" es, para Mumford (1960), el "hombre posthistórico", el hombre de su tiempo, el hombre que vive en un mundo en el cual "todos los objetivos humanos serían absorbidos por un proceso mecánico inmune a cualquier deseo humano que difiera de él" (p. 181). Las sociedades de las ficciones distópicas son siempre sistemas cerrados y totales en los cuales nada debe suceder que no forme parte de su plano estático de existencia. Ello se aplica también a los medios de comunicación, los cuales son representados como partes indisociables de ese mundo como un todo. Son decisivos para la conformación de los sujetos.

El objeto o el medio "libro" tiene gran relevancia en todos los textos, como un símbolo pleno de significados y de transformaciones. En Nosotros (Zamiatin, 1991), se considera que la gran obra que el pasado legó fue "Horarios de Carreteras de Fierro". La producción de libros en curso se refiere a las publicaciones que ofrecen los horarios que todos deben cumplir o textos con finalidad moralizante o doctrinaria. En el Estado Mundial de Un Mundo Feliz (Huxley, 1979), las obras impresas que habrían quedado o que fueran todavía accesibles tratan apenas de cuestiones prácticas. A ellas no les cabe ni siquiera la función de entretener. Es a partir de los libros de Shakespeare, como contrapunto al mundo civilizado, que el salvaje constituirá una noción de vida, especialmente en aquello que se refiere a los sentimientos y a las costumbres, y quien sustentará la discusión con el administrador. Por cierto, el Salvaje se confinó a sentimientos que eran propios de la literatura y concibió una vida completamente en conflicto con el mundo del Londres de Huxley.

De cualquier forma, los libros asumen un simbolismo como representantes de una cultura superior, como registro y preservación de la historia, y sirven como un elemento que sería capaz de desestabilizar al Estado Mundial. La lectura es hecha generalmente a solas y ello podría conducir a un conjunto de actitudes antisociales: complicaría las for- 
mas de control sobre el individuo (por causa del aislamiento) y, tal vez, terminaría generando una reflexión y una conciencia indeseable en un mundo marcado por la felicidad de los anestesiantes químicos y sociales. En 1984 (Orwell, 1981), el libro es un elemento fundamental para la trama gracias al libro de Goldstein. Éste ofrece, al mismo tiempo, una forma de conexión subversiva y esclarecedora y es usado como una técnica de autotraición. Es a través del libro que Winston comprende la dinámica del Partido y, en seguida, es apresado, torturado y transformado. La sensación de libertad ofrecida por el conocimiento sirve apenas para ser sustituido por el real propósito del Partido. De la misma forma los libros pornográficos llegan a las proles y la propia transgresión es calculada como forma de control.

¿Qué hay de verdaderamente subversivo en los enredos de la pornografía barata? En el caso de 1984, apenas la forma de adquisición y ello está programáticamente establecido. Los libros son apenas promesas de mundos que los lectores nunca tendrán realmente. En La Pianola (Vonnegut, 1977), los libros son publicados, a través de clubes de libros, solamente a partir de cálculos de viabilidad, es decir, en función de si reúnen la capacidad de retener la atención de los consumidores/ lectores, si contienen temáticas adecuadas y no ofensivas a la manutención del status quo y si hacen posible una relación satisfactoria de producción industrial. En Farenheit 451 (Bradbury, 1991), el libro es el elemento más importante de la historia justamente por haber sido eliminado como expresión permitida. Estos existen como reminiscencias y son raros y prohibidos. Son vestigios de otros tiempos y terminan transformándose, en el límite, en textos memorizados por algunos pocos individuos que eligen el contenido de los libros como la manifestación superior de la cultura.

El libro es una especie de emulación de lo que el propio ser humano es en las sociedades distópicas. El libro también sufrió transformaciones radicales en esas representaciones y otros autores transfieren a éste las agresiones contra el hombre. Es así que se puede relacionar al hombre de imaginación cientifizada de Nosotros y los libros que contienen apenas cuestiones operacionales. En Un Mundo Feliz se puede observar que los libros deben ser evitados - basta recordar las aplicaciones neopavlovianas para que los niños adquieran aversión al libro- como 
forma de llevar una vida distante de cualquier reflexión o de cualquier pensamiento profundo, y así mantener al hombre en una eterna infancia de placeres inmediatos.

El libro de Goldstein, 1984, no llega a ser una representación de lo que es el libro en términos masivos en Oceanía. Éste tiene una función más específica en la narrativa que la de ser un modelo de medio de comunicación típico de Oceanía. En este sentido, la pornografía barata, creada y fabricada por el Partido, a partir de las máquinas, y distribuida falsamente de forma furtiva, representa mejor al hombre que quedó. Este hombre es montado por el pensamiento del Partido, vive de acuerdo a sus reglas e incluso su transgresión no es más que un artificio. Fue vaciado de cualquier expresión espontánea o creativa.

En el texto de Vonnegut, el libro, así como el hombre, es apenas una unidad mensurable y pasiva en términos de previsión, cálculo, intercambio y acomodación. Ambos son mercancías y atienden las expectativas de una razón tecnológica que les confiere sentido por lo que representan como cifras y nada más. Farenheit 451 revela un hombre que rechazó el protagonismo de la vida y prefirió eliminar lo que significaría su conciencia histórica y cultural: el libro. Su existencia no tiene más la prerrogativa de la inquietud y la propia ausencia del libro como opción representa que el hombre alienado es antes un acto deliberado que una imposición.

Si el libro muestra representaciones ambiguas, los medios de comunicación de masa identificados con los tiempos más recientes serán invariablemente herramientas al servicio de la ingeniería social. El periódico será en Nosotros el vehículo oficial del poder y el único medio disponible como proveedor de informaciones, contrariando el escenario de la mayoría de las ciudades europeas y norteamericanas que ofrecían, por ejemplo, decenas de títulos en ciudades como París o Londres. En Un Mundo Feliz hay periódicos de acuerdo a la capacidad cognitiva de cada casta y, así como los demás medios, tienen el propósito principal de entretener y no de ampliar la visión del mundo de los lectores de forma alguna. La imprenta de Oceanía será un medio relacionado también con el poder; no obstante, Orwell (1981) vislumbra una "nueva" aplicación para el periódico. Éste ofrece el registro mutante de los hechos y radicaliza la idea de un poder que es capaz de actualizar el pasado de 
acuerdo a cada nuevo interés del Partido. En La Pianola ni siquiera se menciona la existencia de periódicos y ello posiblemente está relacionado contextualmente al débil papel que los periódicos tenían ya en cuanto medios imaginados como capaces de modificar a las personas. En Farenheit, éstos simplemente perderían su importancia, perderían sus lectores. La mayoría no los quería más y casi nadie sentía su falta.

Los propósitos de control están claramente presentes en las tres representaciones. En cuanto que en el primero eso se da por medio de un canal único y absolutamente dedicado al Benefactor, en Un Mundo Feliz la integración de la idea de narcotización se refleja en las páginas de los periódicos y ofrece una versión leve y relajada de los hechos. En 1984, el periódico es más bien una posibilidad para hacer transitar hacia la desinformación, desestabilizar la vida, enfatizar la insignificancia del individuo y la omnipotencia inmemorial del Partido.

Los medios de comunicación que tienen como base los sistemas de impresión son creativamente deudores de los periodos anteriores y no llegan a representar los ensayos más fantasiosos o imaginativos que las tecnologías más recientes venían prometiendo en el cambio del siglo XIX hacia el XX. La posibilidad de que las imágenes en movimiento consigan expresar eso de forma más evidente será algo que en los textos distópicos se presentará, una vez más, como tecnologías destinadas a atender demandas relacionadas al control de la población. Esas representaciones, sin embargo, no están presentes en Nosotros. Zamiatin creó su Estado unificado sin cines o pantallas y los eventos en las plazas y las conferencias constantes sirven como los principios equivalentes a las concentraciones de públicos que son proporcionados por los cines. Tampoco hay algo que se parezca a la televisión o a la radio en los hogares.

En Un Mundo Feliz, el escenario es muy diferente, hay cines y pantallas en las casas, en los hoteles y hasta en los hospitales. La relación entre el cine y el sonido son posibles. Sus intenciones son las mismas $\mathrm{y}$ ambos embriagan y ofrecen placeres inmediatos sin provocar ningún tipo de efecto colateral. El cine es proyectado de tal forma que sirve como un sucedáneo de la imaginación y no produce ningún tipo de condición reflexiva capaz de generar conflictos, extrañamientos o dudas. Mantiene al sujeto en su condicionamiento perpetuo. Orwell (1981), siguiendo el principio de crear un lugar sin placeres, imagina 
al cine como un dínamo para el odio que diariamente es abastecido en reuniones públicas. También es aplicado para neutralizar, a través de las imágenes, la agresión al enemigo, basándose en un discurso de legitimación y deshumanización, y la guerra como forma posible de diversión. En Un Mundo Feliz, la descripción de las televisiones es breve, pero su aplicación es evidente y sirve también como distracción. Son sistemas blandos de control, en aquello que se refiere a la agresión y a la invasión, en relación con lo que se hace notar en las representaciones de 1984. Las telepantallas son la expresión máxima de eso y penetran en todos los aspectos de la vida. Sirven para vigilar, adoctrinar y amenazar individualmente.

La televisión, en La Pianola y en Farenheit 451, no servirá como forma de monitoreo del ciudadano. En ambas, ocupa buena parte del "tiempo libre" y transmite contenidos destinados a construir el asentimiento social o a preservar la comodidad a través de la diversión constante en sus programaciones. En este aspecto, la relación con Un Mundo Feliz es inmediata y se percibe que los hechos espectaculares son privilegiados y estimulados como forma de atraer y de mantener la atención de los espectadores. Así como no se habla a través de los periódicos en los Estados Unidos de Vonnegut y Bradbury, tampoco hay más menciones al cine. Las televisiones son absolutas como tecnologías de comunicación, con imágenes en movimiento. En el mundo tecnológico de $L a$ Pianola, ello puede ser asociado al papel que el aparato televisor tiene con la mercadotecnia en la lógica de la industria y del consumo y, todavía más, en el asilamiento de la población dentro de sus hogares superequipados. En Farenheit 451, las pantallas dentro de las casas parecen sustituir la vida que ya no tiene lugar a partir de los individuos. Las pantallas se vuelven el propio espacio en el cual la vida fluye.

La radio, o algo que se asemeje a sus posibilidades, sigue un mismo principio integrador que es posible notar en relación con los otros medios. En Nosotros, los altoparlantes ejecutan las marchas oficiales y son nuevamente la expresión de un modo único y admisible de ser. Huxley imaginó aparatos sonoros presentes en todas partes ejecutando música sintética casi todo el tiempo. En 1984, las telepantallas sirven como sustituto de los radios y también están en todas partes, funcionando sin parar. Una vez más, sin embargo, nada se parece a la música 
divertida y animada de Un Mundo Feliz. La movilidad y la ubicuidad previstas para la radio en Huxley se radicalizan en la representación de Bradbury y aparecen ahí como bocinas acopladas al oído, casi como prótesis. En esta condición, el dispositivo se adecua a la perspectiva de flujo constante. En este caso, hay todavía la "ventaja" de que el aparato esté pegado al cuerpo, haciendo así que haya menos "riesgos" de que se interrumpa la señal.

La cuestión de la radio está vinculada también a su contenido y ahí, especialmente, la música es un elemento recurrente en los textos que merece atención. La música, así como el libro o como el hombre, está convertida en una representación que entra en conflicto con aquello que los autores entienden como la expresión humana creativa y auténtica. El musicómetro, por ejemplo, reduce la música a una ecuación calculada por la máquina. La música sintética ofrece desarrollos agradablemente previsibles y es proyectada/sintetizada en las Oficinas de Propaganda y en las Escuelas de Ingeniería Emocional. En 1984, hay dos tipos de música: una es representada por las marchas al estilo militar, tocadas constantemente por las telepantallas dirigidas a los miembros del Partido; las otras son creadas por el Departamento de Ficción y son hechas para "llegar al gusto" de los Proles. Sirven, casi siempre, para entretener y eventualmente son proyectadas para crear un clima de odio hacia los enemigos externos.

La música en La Pianola presenta dos situaciones que también expresan el desencantamiento del autor: sirve para ciertos programas musicales de televisión y son capaces de ser identificadas incluso sin escucharlas, para ello basta fijarse en la forma como el baterista ejecuta una pieza, por ejemplo; el otro caso es el de la ejecución musical a través de la pianola. El aparato en sí no es ni siquiera algo que pueda considerarse como algo tecnológicamente avanzado, pero la sensación que provoca en uno de los personajes (Hertz) y todo el encantamiento que hay con las máquinas automatizadas, sirve para mostrar la irrelevancia de la creatividad como adjetivo importante en la composición y en la ejecución musical. En Farenheit 451, no hay particularmente mención a la música. Lo único que aparece es referido como theremin (aparato electrónico que emite sonidos a partir de los movimientos del cuerpo), así como la intención de estimular una pieza o un filme con mucho ruido. La 
música parece haber sido finalmente sepultada. En todo ello hay un hombre y una sociedad que proyectan y producen esas condiciones.

Dichas representaciones dicen más cuando se observa cómo ellas se vuelven la síntesis de lo que son esos hombres - o sea, tal como se revelan- en contrapunto a aquello que los autores consideran la verdadera, auténtica, o expresión superior de ese hombre y de esa sociedad. Así, el musicómetro genera éxtasis porque ofrece una música producida artificialmente que toca a la imaginación cientifizada. El cine sensible atrae porque ofrece placer inmediato y no exige un comportamiento reflexivo. Las telepantallas realizan el proyecto de monitoreo del individuo. EPICAC -el supercomputador-es preciso, neutro, impersonal. No se equivoca, en un mundo de decisiones tecnológicas. Las pantallas sustituyen un mundo que no existe más. La normalidad acaba reduciéndose a eso, pero los textos no son contados por personajes normales.

En todos los casos, los narradores representan la anormalidad del modo de vida o del pensamiento corriente. D-503, Winston, Paul y Montag son transformados por la secuencia de acontecimientos. Los dos primeros son al final convertidos completamente en ciudadanos ideales o robots de sus sociedades, y los dos últimos se vuelven marginales en sus mundos. Marx es el anormal que será extirpado de la vida del Estado Mundial y el Salvaje acabará prefiriendo el suicidio delante de la incompatibilidad de la vida antigua en Malpaís con el mundo civilizado. Todos ellos representan el ruido y lo atípico en sus universos sociales, son percibidos como extraños y no sirven para que sus sociedades mantengan el orden y la estabilidad. Todos pasaron también por transformaciones. Las suyas, sin embargo, no caben en el tipo de individuo que interesa a esas sociedades, preocupadas con las transformaciones que conducen al individuo a la uniformidad en Nosotros, a la infantilidad en Un Mundo Feliz, al vaciado en 1984, a la obsolescencia en La Pianola y a la alienación en Farenheit 451.

Dentro de la perspectiva de que el hombre puede ser transformado, los medios de comunicación que anclan, de hecho, también en el gusto y en lo cotidiano de la mayoría de la población considerada genéricamente como "masa", son representados como medios para promover la transformación y la manutención del hombre común en criatura cosificada y, principalmente, bajo control. Los medios de comunicación 
son proyectados como partes de un gran mecanismo que permite tan solo la creación de un estado de control sobre cada individuo, ya que la concepción de masa es la de aquella que acepta pasivamente lo que le es dicho o, hasta cierto punto, para ella no hace mayor diferencia cualquier cosa que no tenga que ver solo con su hedonismo o su sobrevivencia inmediata. A partir de ahí se puede afirmar que existe la creencia de que las tecnologías de comunicación son capaces de ser aplicadas para determinados fines y que alcanzarán esos fines solo con ser operados técnicamente; esto es, de forma que se obtenga un fin usando solamente el método más eficaz.

Los analistas y estudiosos de mediados del siglo XX, en general, consideraban que los medios de comunicación rebajaban el gusto de las masas; las inducían a comportamientos promiscuos y criminales; que seducían por la técnica y no por la reflexión o por la contemplación estética; que exploraban psicológicamente a los públicos; que embrutecían, imbecilizaban y brutalizaban los sentidos; que servían a los sistemas políticos y económicos como forma de infundir el conformismo social y, usando un término de Marcuse (1973), generando una "Conciencia Feliz". Los autores aquí analizados también se inscriben en ese espíritu crítico y poco optimista sobre la forma en que los medios de comunicación venían siendo aplicados y consumidos por la población.

Orwell (1981) pretendió construir una imagen de un futuro que generase más pavor que sus antecesores y, de hecho, lo consiguió. Sus representaciones de las tecnologías de comunicación, a través de las telepantallas, son las que más ostensivamente interpelan a la vida. Hay un principio empotrado en esas representaciones que, ciertamente, es más fuerte que la simple descripción de los aparatos empleados. El monitoreo que conduce a los ejercicios en las mañanas de Winston y ordena que él se incline es, por ejemplo, menos importante que la idea de que existen dispositivos registrando el curso de la vida de cada uno.

En 1984, la presencia de las telepantallas es una regla. No hay la audiencia condicionada de Lenina o Linda de Un Mundo Feliz, el consumo calculado de La Pianola o el voluntarismo hedonista de Mildred en Farenheit 451. La interpelación no es sutil y la pretensión es imponer el miedo como forma de control. La imagen del poder oficial en Nosotros y 1984 es clara y evidencia, como recuerda Gottlieb (2001), su capaci- 
dad para juzgar e imponer el miedo y el terror como las figuras de autoridad. El Bienechor y el Gran Hermano, aunque operando de formas diferentes, no son discretos en sus representaciones. Son el poder. Del mismo modo operan los mecanismos de control y todos saben que la vida es vigilada, puesta sobre los ojos y oídos de guardianes y policías que tratan de mantener el orden a través de la percepción clara de que cada uno está siendo vigilado ininterrumpidamente.

El peligro que se agiganta, no obstante, es el de la dominación que no se manifiesta escandalosamente en plazas y eventos públicos, pantallas y carteles, policías o aparatos de vigilancia. En Un Mundo Feliz, el poder está nominalmente en las manos de 10 administradores, pero la operacionalización es ejecutada por la élite formada por los Alfas, que dominan el conocimiento, tanto para generar vida en el laboratorio como para mantener la sociedad, como un todo, en letargo administrativo. No hay conciencia de que la vida sea completamente instrumental y el complejo tecnológico es mantenido discretamente; sus revelaciones son siempre conducidas para inducir al placer y nunca generan tensión u hostilidad aparente. Todo se conforma en un cuerpo armónico de flujos de mercancías y sentidos excitados. Todo se reduce a eso.

En La Pianola o Farenheit 451, hay derivaciones de ese sistema. En La Pianola, no obstante, la élite formada por los administradores e ingenieros desarrolló una forma de manutención del poder que se legitima por la racionalidad que le sería intrínseca. La idea es objetiva: los más capaces intelectualmente deben gobernar. Claro, esa noción de capacidad es determinada de acuerdo con ciertos presupuestos; sin embargo, ello está institucionalizado y se transformó en realidad posible. El control sobre la vida pasa por la misma perspectiva racional y la trayectoria de cada ciudadano es registrada en los sistemas informáticos. Así, cada individuo se transforma en un perfil de posibilidades y limitaciones a partir de las ecuaciones procesadas por las computadoras y puede ser evaluado en sus competencias para ejercer ese o aquel otro cargo o hasta ser considerado un posible saboteador. El argumento de defensa y de justificación de ese modo de gobernar y determinar el destino de los sujetos está basado en una racionalidad tecnológica que provee la vida de la forma materialmente más eficaz. Ninguna decisión es personal, todo es neutro y, por ello, es superior. 
De cualquier forma, esa élite, ese origen de la dominación es identificada. Incluso se orienta hacia la discreción, pero no es absolutamente invisible. Podría llegar a ser cuando EPICAC se ocupara de todas las tareas administrativas y no quedara más espacio para los cargos decisivos, pero eso es una hipótesis en el texto. En Farenheit 451, no hay más posibilidad de identificar el poder subyacente a la sociedad. Los bomberos son el rostro más visible y parecen desempeñar papeles más bien dramáticos que estratégicos. El propio Sabueso Mecánico se manifiesta más como una estrella de programas de televisión que como un agente fundamental en el control social. La sociedad está bien acomodada en el papel que escogió como suyo y se conforma con aquello que abastece sus sentidos. Para mantener el control sobre los pocos que son considerados como subversivos no es necesario mucho empeño; basta continuar manteniendo el estado de las cosas así como se encuentra. Las mercancías y las transmisiones de los medios de comunicación continuarán sustituyendo la vida hasta, quién sabe, el tiempo en que ellos serán la propia vida. Ya no es posible otra forma de pensamiento y de modo de vida; el hombre es finalmente, usando un concepto de Marcuse (1973), unidimensional.

\section{CONSIDERACIONES FINALES}

Los medios de comunicación y los diversos aparatos técnicos representados en los textos están completamente integrados al modo de organización de esas sociedades. Esa integración, no obstante, es antes el resultado de una intención de dominación que una manifestación representativa del todo social como una expresión independiente. Tales representaciones se constituyen a partir de un principio: esos medios y esos aparatos son, sobre todo, tecnologías de transformación del hombre. Y, para alcanzar ese fin, independientemente de lo que se pretenda específicamente en cada uno de los textos, es necesario descifrar al hombre, volverlo un objeto comprensible. Después de decodificarlo es posible, finalmente, reprogramarlo.

En textos como Nosotros, Un Mundo Feliz y 1984, las intervenciones parecen ser más fantasiosas, radicales y hasta improbables. Hasta es posible encontrar alguna verosimilitud con las formas de comunicación narcotizantes de Un Mundo Feliz, pero de ahí surge luego la protección 
y el distanciamiento que se puede imaginar en relación con los individuos fabricados biológica y psicológicamente en laboratorios. Se puede decir, con alivio, que eso no se parece a la realidad.

La Pianola y Farenheit 451 son menos fantásticas y el hombre no parece tan diferente a la realidad. La propia noción de transformación está representada de forma menos evidente. No obstante, se ocupa todavía de ello. El hombre, cada vez más, se vuelve menos consciente de que él es parte de esos medios, que vive a través de ellos, que tiene la vida representada en ello. Y los medios y los aparatos solo son partes indisociables del todo que se torna una sola cosa y tiene una razón de ser y de significar apenas dentro de la propia lógica. Todo se funde y no se nota más el fin porque todo ya se convirtió en medio. Cuanto menos distinguible se vuelve el hombre del medio que lo engloba, tanto más eficiente se vuelve la sociedad como modelo tecnológico de producción (revelación).

En las visiones, por tanto, de futuros ruines, los medios de comunicación se convertirían apenas en catalizadores de la dominación. Es con ellos, o a partir de ellos, que sería posible reducir al hombre. Esa reducción hará de él una creatura incapaz de percibir el destino porque la vida toda sucede solo dentro de un plano que es exterior al individuo.

Lidiar con la forma como el hombre es concebido o como él piensa su destino resuena siempre como una preocupación necesaria. La idea de que el hombre pueda ser fungible, de que pueda ser abstraído al punto de que pueda convertirse en unidad calculable y planificada, puede ser todavía evaluada como una crítica social válida y, más que eso, actualizada. En la medida en que las relaciones entre los medios de comunicación, la sociedad y el individuo son cuestiones en las cuales la noción de poder y de control se vuelven más empañosas, más todavía debe revelarse la aprehensión delante de esa organización integralizadora y totalizante sobre la cual se tienden a perder de vista sus contornos.

Los medios de comunicación son imaginados como tecnologías de transformación del hombre y son fundamentales para mantener el poder. El hombre, sobre esa perspectiva, puede ser modificado y administrado también a través de esos medios. Tal mantenimiento se resume al hecho de hacer al individuo abdicar de cualquier actitud disonante de aquello que se define como el modo estandarizado de estabilidad de esas sociedades. El éxito de dichos sistemas de dominación, cuyo 
propósito es la totalización del pensamiento, se vuelve más eficiente a medida que ese hombre se revela como indiferente a dichos sistemas o se siente satisfecho con su condición.

La perfección social, en esas distopías, es imaginada como la posibilidad de que el hombre se transforme en objeto descifrable y cifrable, disponible y moldeable. En esas condiciones todo, finalmente, se integra. Ahí nada más sucede, todos se toman por felices, se piensa que la civilización habría alcanzado el nivel más espectacular de todos los tiempos. El ser humano no es más el hombre y no se imagina ninguna vida diferente de la ahí planteada. Paradójicamente, nada de ello es la manifestación de un ingenio maquinístico, de un cerebro electrónico o de algún ente tecnológico autónomo que pretende subyugar al hombre. Son escenarios excesivamente humanos.

\section{Bibliografía}

Bacon, F. (2006). La nueva Atlántida. Madrid, España: Akal.

Booker, M. K. (1994a). Dystopian literature: A theory and research guide. Westport, EE.UU.: Greenwood.

Booker, M. K. (1994b). Dystopian impulse in modern literature: Fiction as social criticism. Westport, EE.UU.: Greenwood.

Bradbury, R. (1991). Farenheit 451. Madrid, España: Círculo de Lectores.

Collins, S. (2008). The hunger games. Nueva York, EE.UU.: Scholastic Press.

Ellul, J. (1968). A técnica e o desafio do século. Río de Janeiro, Brasil: Paz e Terra.

Fogg, W. L. (1975). Technology and dystopia. En P. E. Richter (Ed.), Utopia/dystopia? (pp. 57-73). Cambridge, EE.UU.: Schenkman.

Gottlieb, E. (2001). Dystopian fiction east and west. Toronto, Canadá: McGilligan Books.

Greenberg, M., Olander, J. H. \& Rabkin, E. (1983). No place else: Explorations in utopia and dystopian fiction. Carbondale, EE.UU.: Southern Illinois University Press.

Heidegger, M. (2002). Ensaios e conferências. Petrópolis, Brasil: Vozes. Hillegas, M. R. (1967). The future as nightmare: H. G. Wells and the anti-utopians. Londres, Inglaterra: Oxford University Press. 
Huxley, A. (1979). Un mundo feliz. Barcelona, España: Plaza y Janés. Jacoby, R. (2001). O fim da utopia. Río de Janeiro, Brasil: Record. Jacoby, R. (2007). Imagem imperfeita: pensamento utópico para uma época antiutópica. Río de Janeiro, Brasil: Civilização Brasileira.

Kateb, G. (1972). Utopia and its enemies. Nueva York, EE.UU.: Shocken Books.

Kumar, K. (1987). Utopia and anti-utopia in modern times. Oxford, Inglaterra: Basil Blackwell.

Kumar, K. (2006). Da sociedade pós-industrial à pós-moderna: novas teorias sobre o mundo contemporâneo. Río de Janeiro, Brasil: Jorge Zahar.

Marcuse, H. (1969). O fim da utopia. Río de Janeiro, Brasil: Paz e Terra. Marcuse, H. (1973). A ideologia da sociedade industrial: o homem unidimensional. Río de Janeiro, Brasil: Zahar.

Marcuse, H. (1999). Tecnologia, guerra e fascismo. São Paulo, Brasil: Editora Unesp.

Mumford, L. (1956). A condição de homem: uma análise dos propósitos e fins do desenvolvimento humano. Porto Alegre, Brasil: Globo. Mumford, L. (1960). Las transformaciones del hombre. Buenos Aires, Argentina: Sur. [Trabajo original publicado en Nueva York, EE.UU. en 1956].

Negley, G. \& Patrick, J. M. (1952). The quest for utopia: An anthology of imaginary societies. Nueva York, EE.UU.: Henry Schuman.

Orwell, G. (1981). 1984. Madrid, España: Salvat.

Richter, P. (1975). Utopia/dystopia? Cambridge, MA, EE.UU.: Schenkman.

Vonnegut Jr., K. (1977). La pianola. Barcelona, España: Bruguera.

Walsh, C. (1976). From utopia to nightmare. Evanston, IL/Nueva York, EE.UU.: Harper \& Row.

Williams, R. (1992). Historia de la comunicación: de la imprenta a nuestros dias. Barcelona, España: Bosch.

Zamiatin, E. (1991). Nosotros. Barcelona, España: Tusquets.

Fecha de recepción: 30/08/12. Aceptación: 11/01/13. 